Review Article

\section{A systemic review on various pertinences and simulations of rotavirus}

\author{
Sameer Sharma* and Seema Rani Padhiary \\ Department of Bioinformatics, BioNome Private Limited, Bangalore, 560043, India
}

\section{Abstract}

Rotavirus induced disease are a main source of dreadful, serious and drying out gastroenteritis in kids (less than five years old). Instead of the worldwide presentation of immunizations for rotavirus longer than 10 years back, rotavirus infections still result in more than 200,000 yearly passings, generally in developing countries. Rotavirus basically infects enterocytes and cause diarrheal through the demolition of absorptive enterocytes. Intestinal secretions are invigorated by rotavirus (non-auxiliary/structural protein) to enactment of the enteric sensory system. Rotavirus diseases can prompt viraemia and antigenaemia (term related with more serious indications of intense gastroenteritis). Rotavirus reinfections are regular throughout the life, even though the sickness seriousness is diminished with rehash contaminations. The resistant relates of assurance against rotavirus reinfection and recuperation from disease is inadequately perceived. This study takes a step forward to the administration of rotavirus disease centers, primarily on control and cure of dehydration, even though the utilization of antiviral and hostile to purgative medications can be demonstrated at some cases.

\author{
More Information \\ *Address for Correspondence: Sameer Sharma, \\ Department of Bioinformatics, BioNome Private \\ Limited, Bangalore, 560043, India, \\ Tel: 08860922305; \\ Email: sameer21.97@gmail.com; info@bionome.in \\ Submitted: April 07, 2021 \\ Approved: April 27, 2021 \\ Published: April 28, 2021 \\ How to cite this article: Sharma S, Padhiary SR. \\ A systemic review on various pertinences and \\ simulations of rotavirus. Int J Clin Virol. 2021; 5 : \\ 041-046.
}

DOI: 10.29328/journal.ijcv.1001034

ORCiD: orcid.org/0000-0002-3456-0263

Copyright: @ 2021 Sharma S, et al. This is an open access article distributed under the Creative Commons Attribution License, which permits unrestricted use, distribution, and reproduction in any medium, provided the original work is properly cited.

Check for updates

OPEN ACCESS

\section{Introduction}

Rotavirus belongs from the family of Reoviridae and contains 11 segments of dsRNAs that are enveloped by the complex architecture of three concentric capsids. It has six structural proteins and six non - structural proteins encoded by RNA segments which are covering the dsRNAs. The mature virus contains a protein that regulates the cell entry, enzymatic functions and specificity, which are useful for generation of viral transcript and initiation of immune response. Replication of genome and innate immune response are induced by the non-structural protein (NSP4 main role) [1]. Mainly, 10 species of rotavirus have considered based upon the sequence. In infants, the most common infecting disease is affected by rotavirus species A which has VP7 \& VP4 segments that contains various types of genotypes that are based on the length of the sequence. VP7 (Rotavirus A species) has dual nature of nomenclature that represents the glycoprotein and VP4 protein subtypes [2]. Banafild WG, states that the six G type strains and 3 P-type strains of Rotavirus has been observed. Globally, rotavirus is a severe disease, and the virus infectacute gastroenteritis, mostly in case of infants, young children, and also life-sinister throughout the world. According to the studies, low - income countries are affected by more than 5 lakh death rates all over the world [3] (Table 1 \& Figure 1).

\begin{tabular}{|c|c|}
\hline \multicolumn{2}{|c|}{ Table 1: Scientific Classification of Rotavirus. } \\
\hline Kingdom: & Orthornavirae \\
\hline Division: & Duplornaviricota \\
\hline Class: & Resentoviricetes \\
\hline Order: & Reovirales \\
\hline Family: & Reoviridae \\
\hline Genus: & Rotavirus \\
\hline Species: & Rotavirus A-J \\
\hline
\end{tabular}

Watery exertion or diarrheal is common symptoms in infected peoples that leads to the dehydration of the body. Barlett, (2000) revealed that the Rotavirus type A strain is more infectious with having the ability to transmit from animals to humans [5]. RVGE (Rotavirus gastroenteritis), and the details were estimated for potential impact about the vaccination. The largest number of expected cases of RVGE had helped to quantify granular distributions and monitoring the vaccination process for infected rotavirus patients. Barlett, (2000) also observed that some symptoms like diarrheal and vomiting are the main symptoms observed in humans as well as in animals such as piglets, rabbits, deer, etc.

\section{Epidemiology}

\section{Global burden}

Rotavirus is pervading the infection to every child, who is 


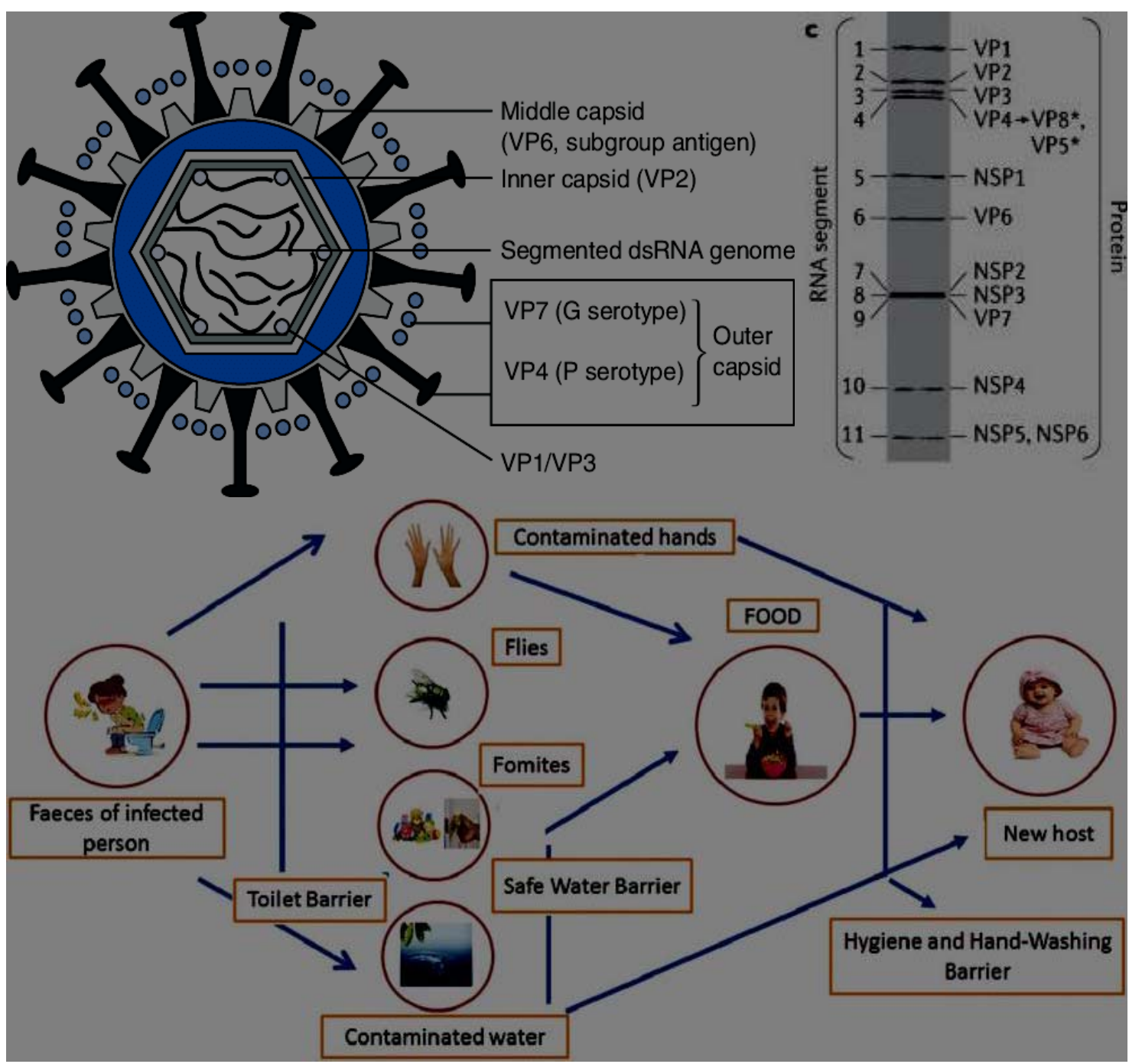

Figure 1: Rotavirus schematic structure contains inner capsid layer and Encoded proteins for simian rotavirus [4]. Pathology of Rotavirus [34].

3-5 years old, and infants throughout the world [5]. Santos, et al. (2005) observed that children who are affected by rotavirus are usually less than 5-year-old and 2.3 million cases were hospitalized out of 24 million patients [6]. In 2013, some studies revealed that harmful symptoms were observed in less than 5 years of age suffering from rotavirus infection globally. Most influencing rotavirus strains is G9P [6], and in India, multicentre assortment observed that $9.5 \%$ people's are influenced from all rotavirus species.

Primarily, the epidemiology and pathophysiology of Rotavirus ' $\mathrm{A}$ ' species include innate and adaptive immune response to rotaviruses, clinically manifestations, preventions and summarizes about impact of rotavirus. Globally, each country should contain these vaccines because treatment should be given at the exact time, to stop the spreading of infection in the body. These types of viruses are transmitted to other people very rapidly. There is variation in doses number, ages of the target, and actual coverage. Rotavirus induced diarrhea has more than normal countseverity and only alimited proportion of diarrheic patient are cured by home care and require hospitalization [7]. According to the Sanderson, et al. reports, it has been observed that, rotavirus $\mathrm{A}, \mathrm{B}$, and $\mathrm{C}$ were found in human. In all the groups of rotaviruses, only ' $A$ ' group has infected in most of the cases of humans. The occurrence of serotype has been observed in highly populated countries in the world. Tremendous spreading of the rotavirus disease to the societies and it can be the most danger during winter season $[8,9]$.

Woode, et al. 2012, EDIM (Epizootic Diarrhea of Infant Mice); the infected cells in both nucleus \& cytoplasm which contains membrane tubules and virus particle consist from same length in the cytoplasm [9]. It was also demonstrated by complement fixation (CF) about all animals and human contain a distributed group of antigens in the fecal sample which involved in the infected rotavirus disease. The bovine rotavirus comes under the density gradient approximately $1.37 \mathrm{~g} / \mathrm{ml}$, and virus particles are identified through the outer layer of the capsid, like single-shelled particles [10]. Inner layer of capsid get adhere to the antibodies, and the origin of the sera were detected. The single-shelled rotavirus residues collected from different animal species were agglutinated by all convalescent sera was tested. In case of partial \& complete 
cross-reaction, it was done by employing the double-shelled human rotavirus residues with antiserum to the human virus. Woode, et al. 2012 observed the antigen group on the virus inner capsid and sera which could neutralize the virus tests and antigens reaction.

\section{Effects of vaccination}

Some studies revealed that the first rotavirus vaccine has launched the schedule for national childhood immunization, which was made compulsory in all hospitalizations for each student who has symptoms of rotavirus. And the vaccine was exported to all over the country as well as lunched in the market. According to the Woode, et al. reports, all the collected samples from high and low income countries, the report suggested that rich country children are not eligible for the rotavirus vaccination process because of the herd immunity, but herd immunity or indirect protection for vaccination was not observed in the Low income countries. The reason for this situation was not clear until now [11].

According to the national schedule for immunization, statistical graph shows decrease in the rotavirus infection patient cases because the vaccine was launched, and after vaccination the spreading of disease was controlled worldwide. After the vaccine came to existence, the cases were decreased. The rotavirus disease was observed in the children's and old age peoples because the people were coming in the contact of infected people [12]. After the vaccination was launched, it was reported that different rotavirus strains contain diverse genotype based variation in case of vaccination [13]. Rotavirus G2P strains [4] were observed in many countries, where they launched G2 genotype based pentavalent rotavirus vaccine for effective results. This strain was initially noticed in Brazil; where G2P-induced diarrhoea showed an effective reaction against the monovalent G1P [14] rotavirus vaccine consequently preventing the disease.

\section{Transmission}

Rotavirus transmits the disease through fecal matter, and person to person through close contacts [15]. Some of the viruses strains need a host to get transmit, after the production virus protein produced by the host, and it leads to destroy the host cell to decrease the immunity [16-19].

The pathogen can transmit from one place to another and infected the whole area of hospitals with the help of various objects [20]. The report suggests that researchers have assumed rotavirus is an airborne disease that is getting transmitted to infect the healthy person, and they are trying to produce the more effective vaccines which can produce the antibody in our body.

\section{Mechanism of rotavirus replication}

Rotavirus initiates replication process in top and middle villi of small intestine via non - dividing enterocytes.

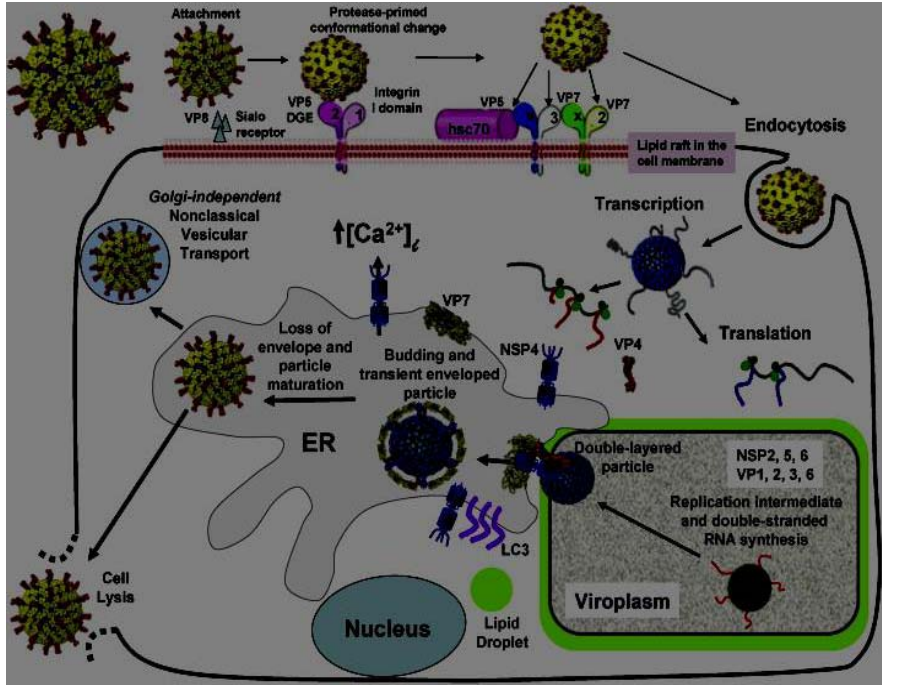

Figure 2: Mechanism of Rotavirus Replication Cycle.

Enteroendocrine cells and mature enterocytes susceptibility towards rotavirus infection was shown in mice and HIE (Human Intestinal Enteroid) cultures. Outer capsid proteins along with host cell surface molecules like HBGA (Histo blood group antigens) and sialoglycans; mediate the attachment of rotavirus to host cell (Figure 2).

Sanderson, et al. (2011) states that rotavirus needs more expression factors for replicating, infecting, and destroying the host cells [21]. Groome, et al. observed that human enteroendocrine cell line in mice (transformed version) are responsible for the infection in the mature enteroendocrine and enterocytes cells. Rotavirus will be attached to the surface of the enterocyte microvilli of the small intestine cell and binds to the host cell with the help of a receptor. The outer capsid proteinVP4 (through its VP8* domain) binds to the surface of the host cell (gangliosides GM1 and GD1a) and HBGAs (Histo-blood group antigens) [22]. In Africa, rotavirus infection in children is caused by the Lewis-negative glycan phenotype. HBGA expression contains genetic changes, which shows distinct changes in rotavirus genotypes [22] because of enriching regulated precursor HBGA, and the high prevalence of $\mathrm{P}$ genotype. The Rotavirus vaccine strain is the vulnerable in nature and the vaccine efficacy. Rotavirus is capable for the producing multiple copies of itself in the cytoplasm and leaving the host cell after damaging through cell lysis [23].

\section{Gastrointestinal symptoms}

On the contrary to the microbial pathogens induced gastrointestinal infection and diarrhea, rotavirus infections leads to serious infections which can lasts for a short time of period. Rotavirus induced non - inflammatory diarrhea has two different perspectives: a) secretary diarrhea due to the effects of activation of enteric nervous system and b) osmotic diarrhea due to mal - absorption

Some symptoms for gastrointestinal infection by rotavirus are; 
- Heartburn and Acid Reflux

- Indigestion or Dyspepsia

- Gallstone Pancreatitis

- Nausea and Vomiting

- Peptic Ulcer

- Belching and Bloating

- Abdominal Pain

- Gallbladder Disorders, Biliary Tract Disorders and Gallstone Pancreatitis

\section{Diagnosis, screening, and prevention}

Rotavirus infection can be detected through blood as systemic infection was caused due to enrollment of rotavirus in blood stream although intestinal infection is the main symptom but the presence of viral antigen in serum confirmed that not intestine but serum is the site of initial infection. Groome, et al. states that the children suffering from antigenaemia had more chances of severe rotavirus infection as compared to the healthy ones, but a very less proportion of the children with extra- intestinal presentations was found with antigenaemia [24]. Non-immunological response and various other expression factors of rotavirus receptors like HBGA regulate the clearance of rotavirus infection. Rotavirus is initially considered by the Pattern Recognition Receptors in cells or enterocytes of the immune system.

Even though children suffers from various type of persistent rotavirus infections, but the severity is diminished effectively. The level of whole serum present in rotavirus specific immunoglobulin A are currently the best molecular marker of inhibition or protection from persistent rotavirus infection observed in children with SCID (severe combined immunodeficiency disease) and can lead to systemic and chronic rotavirus infection in intestine.

\section{Innovations in rotavirus combat}

ROTAVAC is a vaccine that shows indigenous innovation and a revolutionary improvement in the benefit and treatment of the rotavirus infection in developing countries. In India, Bharat Biotech's vaccine is the first vaccine which is pre-clinically tested for efficacy in India. ROTAVAC's success is a novel framework that embrace and protect innovation. Antibiotics are incapable of treating or preventing infections because they are viral rather than bacterial. Oral rehydration therapy (ORT), a simple fluid replacement using a solution of water, sugar, and salts, has proven effective, inexpensive, and easy to administer in developing countries. That means ROTAVAC is a crucial, long-term solution for those in lowincome countries who otherwise rely upon short-term subsidies from Gavi, the Vaccine Alliance, to access and afford necessary vaccinations.

\section{Prevention for rotavirus disease}

Improvements in sanitation don't considerably diminish the problem of rotavirus disease. The vaccination in contrast to rotavirus is the best way to intercept from infection. RV5 vaccine and RV1 vaccine are the two widely used vaccines around the world $[25,26]$. The RV5 vaccine from Merck (USA) is a type of live attenuated vaccine; made up of 5 human bovine reasserted rotavirus strain ( $\mathrm{G}$ - type strains) whereas RV1 vaccine from Glaxo Smith Kline (Belgium) is a type of live attenuated and monovalent human virus vaccine containing rotavirus strains; initially isolated from rotavirus induced gastroenteritis. These two vaccines showed recommendable effectiveness in rotavirus prevention in highly developed countries but are less effective in developing countries due to some unknown factors [27].

Genetic makeup of host and presence of maternal antibodies can also affect the immunogenicity of rotavirus [28]. First most licensed vaccine of rotavirus was launched in USA and named as Rotashield being a link between intussusceptions and rotavirus infection. Moreover, a number of vaccines are in developing stage and RV1 and RV5 vaccines are the mostly used vaccines across the world. Rotavirus can also lead to asymptomatic infections with specific rotavirus strain associated with protection in contrast to disease infection.

\section{Drug therapies}

According to the reports, rotavirus infection causing diarrheal disease is treated by the many antiviral therapies, and it is mostly in preclinical stages. Nitazoxanide, a broadspectrum antiviral drug used to treat, and decrease the level of diarrheal disease, and acute rotavirus infection [29,30] inhibiting the rotavirus replication in the host cell.

Studies revealed that all rotavirus-associated strains causing gastrointestinal symptoms get reduced because of placebo treatment for children at the age of 5 months to 7 years.

One dose of ondansetron can decrease the level of intravenous rehydration, which is causing diarrheal disease. More than one dose of ondansetron can cause harmful impacts on our body systems.

Smectite (a natural adsorbent that binds to endotoxins, exotoxins, bacteria, and viral particles) has reduced the level of acute diarrheal. And still, we need improvement in the drug treatment [31-39].

\section{Development of vaccines}

Transmission of rotavirus is suggested to have involvement of mutation which allows the rotavirus and HBGA (Histo blood group antigen) interaction. Interspecies transmission must be monitored to completely understand the restriction of host [40]. Although; the rotavirus vaccination has almost $80 \%$ 
effectiveness in contrast to severe rotavirus disease in high income countries and helps to generate a level of rotavirus specific antibodies enough for the neutralization of virus. It is necessary to study the interconnection and protection to improve the current vaccines and initiate the development of more effective next generation vaccines [41]. Moreover, all licensed rotavirus vaccines are live attenuated vaccines which can revert to harmfulness in prematurely born children and can reassert with the human wild type rotavirus [42].

\section{References}

1. Ali A, Kazi AM, Cortese MM, Fleming JA, Moon S, et al. Impact of withholding breastfeeding at the time of vaccination on the immunogenicity of oral rotavirus vaccine-a randomized trial. PLoS One. 2015; 10: e0127622.

PubMed: https://pubmed.ncbi.nlm.nih.gov/26035743/

2. Aliabadi N, Tate JE, Haynes AK, Parashar UD. Sustained decrease in laboratory detection of rotavirus after implementation of routine vaccination-United States, 2000-2014. MMWR. Morb. Mortal. Wkly Rep. 2015; 64: 337-342.

3. Angel J, Franco MA, Greenberg HB. Rotavirus immune responses and correlates of protection. Curr Opin Virol. 2012; 2: 419-425.

PubMed: https://pubmed.ncbi.nlm.nih.gov/22677178/

4. Ansari SA, Springthorpe VS, Sattar SA. Survival and vehicular spread of human rotaviruses: possible relation to seasonality of outbreaks. Rev Infect Dis. 1991; 13, 448-461.

PubMed: https://pubmed.ncbi.nlm.nih.gov/1866549/

5. Armah GE, Sow SO, Breiman RF, Dallas MJ, Tapia MD, et al. Efficacy of pentavalent rotavirus vaccine against severe rotavirus gastroenteritis in infants in developing countries in sub-Saharan Africa: a randomised double-blind, placebo-controlled trial. Lancet. 2010; 376: 606-614. PubMed: https://pubmed.ncbi.nlm.nih.gov/20692030/

6. Arias CF, Silva-Ayala D, López S. Rotavirus entry: a deep journey into the cell with several exits. J Virol. 2015; 89: 890-893. PubMed: https://www.ncbi.nlm.nih.gov/pmc/articles/PMC4300671/

7. Ball JM, Tian P, Zeng CQ, Morris AP, Estes MK. Age-dependent diarrhea induced by a rotaviral nonstructural glycoprotein. Science. 1996; 272; 101-104.

PubMed: https://pubmed.ncbi.nlm.nih.gov/8600515/

8. Banfield WG, Kasniф G, Blackwell AN. Further observations on the virus of epizootie diarrhoea of infant mice: an electron microscopic study. Virology. 1968; 36: 41-42L.

9. Bányai K, Kemenesi G, Budinski I, Földes F, Zana B, et al. Candidate new rotavirus species in Schreiber's bats, Serbia. Infect. Genet Evol. 2017; 48: 19-26.

PubMed: https://pubmed.ncbi.nlm.nih.gov/27932285/

10. Bartlett AV, Moore M, Gary GW, Starko KM, Erben JJ, et al. Diarrhea illness among infants and toddlers in day care centres, I. Epidemiology and pathogens. J Pediatr. 1985; 107: 495-502

PubMed: https://pubmed.ncbi.nlm.nih.gov/2995628/

11. Bartlett AV, Moore M, Gary GW, Starko KM, Erben JJ, et al. Diarrheal illness among infants and toddlers in day care centres, II. Comparison with day care homes and households. J Pediatr. 1985; 107: 503-509.

12. Becker-Dreps S, Vilchez S, Bucardo F, Twitchell E, Choi WS, et al. The association between fecal biomarkers of environmental enteropathy and rotavirus vaccine response in Nicaraguan infants. Pediatr Infect Dis J. 2017; 36: 412-416.

PubMed: https://pubmed.ncbi.nlm.nih.gov/27977553/

13. Bhowmick R, Halder UC, Chattopadhyay S, Chanda S, Nandi S, et al. Rotaviral enterotoxin nonstructural protein 4 targets mitochondria for activation of apoptosis during infection. J Biol Chem. 2012; 287: 35004-35020.

PubMed: https://pubmed.ncbi.nlm.nih.gov/22888003/
14. Bines JE, At Thobari J, Satria CD, Handley A, Watts E, et al. Human neonatal rotavirus vaccine (RV3-BB) to target rotavirus from birth. N Engl J Med. 2018; 378: 719-730.

PubMed: https://pubmed.ncbi.nlm.nih.gov/29466164/

15. Bishop RF, Davidson GP, Holmes IH, Ruck B. Detection of a new virus by electron microscopy of faecal extracts from children with acute gastroenteritis. Lancet. 1974; 149-I5I.

16. Bishop RF, Barnes GL, Cipriani E, Lund JS. Clinical immunity after neonatal rotavirus infection. A prospective longitudinal study in young children. N Engl J Med. 1983; 309: 72-76.

PubMed: https://pubmed.ncbi.nlm.nih.gov/6304516/

17. Bishop RF. Natural history of human rotavirus infections. In: Kapikian AZ (ed) Viral infections of the gastrointestinal tract, 2nd edn. Marcel Dekker, New York, 1994; 131-167.

18. Boshuizen JA, Reimerink JHJ, Korteland-van Male AM, van Ham VJJ, Koopmans MPG, et al. Changes in small intestinal homeostasis, morphology, and gene expression during rotavirus infection of infant mice. J Virol. 2003; 77: 13005-13016.

PubMed: https://www.ncbi.nlm.nih.gov/pmc/articles/PMC296055/

19. Boshuizen JA, Rossen JWA, Sitaram CK, Kimenai FPP, SimonsOosterhuis $\mathrm{Y}$, et al. Rotavirus enterotoxin NSP4 binds to the extracellular matrix proteins laminin- $\beta 3$ and Fibronectin. J Virol. 2004; 78: 10045-10053.

PubMed: https://www.ncbi.nlm.nih.gov/pmc/articles/PMC514988/

20. Bucardo F, Rippinger CM, Svensson L, Patton JT. Vaccinederived NSP2 segment in rotaviruses from vaccinated children with gastroenteritis in Nicaragua. Infect Genet Evol. 2012; 12: 1282-1294. PubMed: https://pubmed.ncbi.nlm.nih.gov/22487061/

21. Burnett E, Jonesteller CL, Tate JE, Yen C, Parashar UD. Global impact of rotavirus vaccination on childhood hospitalizations and mortality from diarrhea. J Infect Dis. 2017; 215: 1666-1672.

PubMed: https://pubmed.ncbi.nlm.nih.gov/28430997/

22. Burnett E, Lopman BA, Parashar UD. Potential for a booster dose of rotavirus vaccine to further reduce diarrhea mortality. Vaccine. 2017; 35: 7198-7203.

PubMed: https://pubmed.ncbi.nlm.nih.gov/29169893/

23. Butz AM, Fosarelli P, Dick J, Cusack T, Yolken R. Prevalence of rotavirus on high-risk fomites in day-care facilities. Pediatrics. 1993; 92: 202-205.

PubMed: https://pubmed.ncbi.nlm.nih.gov/8393172/

24. Clark A, Black R, Tate J, Roose A, Kotloff K, et al. Estimating global, regional and national rotavirus deaths in children aged , 5 years; current approaches, new analyses, and proposed improvements. PLoS One. 2017; 12: e0183392.

PubMed: https://pubmed.ncbi.nlm.nih.gov/28892480/

25. Chen CC, Huang JL, Chang CJ, Kong MS. Fecal calprotectin as a correlative marker in clinical severity of infectious diarrhea and usefulness in evaluating bacterial or viral pathogens in children. J Pediatr Gastroenterol Nutr. 2012; 55: 541-547. PubMed: https://pubmed.ncbi.nlm.nih.gov/22699836/

26. Chen MY, Kirkwood CD, Bines J, Cowley D, Pavlic D, et al. Rotavirus specific maternal antibodies and immune response to RV3-BB neonatal rotavirus vaccine in New Zealand. Hum Vaccin Immunother. 2017; 13: 1126-1135.

PubMed: https://pubmed.ncbi.nlm.nih.gov/28059609/

27. Chilengi R, Simuyandi M, Beach L, Mwila K, Becker-Dreps S, et al. Association of maternal immunity with rotavirus vaccine immunogenicity in Zambian infants. PLoS ONE. 2016; 11: e0150100. PubMed: https://pubmed.ncbi.nlm.nih.gov/26974432/

28. Correia JB, Patel MM, Nakagomi O, Montenegro FMU, Germano EM, et al. Effectiveness of monovalent rotavirus vaccine (Rotarix) against severe diarrhea caused by serotypically unrelated G2P[4] strains in Brazil. J Infect Dis. 2010; 201: 363-369.

PubMed: https://pubmed.ncbi.nlm.nih.gov/20047501/ 
29. Cruickshank JC, Axton JHM, Webster OR. Viruses in gastroenteritis. Lancet. 1974; I353.

30. Das JK. The effect of antiemetics in childhood gastroenteritis. BMC Public Health. 2013; 13: S9-S13.

31. Das RR, Sankar J, Naik SS. Efficacy and safety of diosmectite in acute childhooddiarrhoea:ameta-analysis. ArchDisChild.2015;100:704-712. PubMed: https://pubmed.ncbi.nlm.nih.gov/25784748/

32. Davidson GP, Barnes GL. Structural and functional abnormalities of the small intestine in infants and young children with rotavirus enteritis. Acta Paediatr. Scand. 1979; 68: 181-186.

33. Davidson GP, Bishop RF, Townley RRW, Holmes IH, Ruck BJ. Importance of a new virus in acute sporadic enteritis in children. Lancet. 1975a; 242-246.

34. Doro R, László B, Martella V, Leshem E, Gentsch J, et al. Review of global rotavirus strain prevalence data from six years post vaccine licensure surveillance: is there evidence of strain selection from vaccine pressure? Infect Genet Evol. 2014; 28: 446-461. PubMed: https://pubmed.ncbi.nlm.nih.gov/25224179/

35. Dupont C, Foo JLK, Garnier P, Moore N, Mathiex-Fortunet H, et al. Oral diosmectite reduces stool output and diarrhea duration in children with acute watery diarrhea. Clin Gastroenterol Hepatol. 2009; 7: 456-462. PubMed: https://pubmed.ncbi.nlm.nih.gov/19268266/

36. Echeverria P, Blacklow NR, Cukor GG, Vibulbandhitkit $S$,
Changchawalit $\mathrm{S}$, et al. Rotavirus as a cause of severe gastroenteritis in adults. J Clin Microbiol. 1983; 18: 663-667.

PubMed: https://www.ncbi.nlm.nih.gov/pmc/articles/PMC270871/

37. Emparanza Knörr Jl. Systematic review of the efficacy of racecadotril in the treatment of acute diarrhoea [Spanish]. An Pediatr. 2008; 69: 432-438.

38. Emperador DM, Velasquez DE, Estivariz CF, Lopman B, Jiang B, et al Interference of monovalent, bivalent, and trivalent oral poliovirus vaccines on monovalent rotavirus vaccine immunogenicity in rural Bangladesh. Clin Infect Dis. 2016; 62: 150-156. PubMed: https://pubmed.ncbi.nlm.nih.gov/26349548/

39. Estes MK, Greenberg HB. in Field's Virology (eds Knipe DM, Howley PM) 1347-1401, Lippincott Williams \& Wilkins. 2013.

40. Fauvel M, Svence L, Bamtv LA, Petro R, Bloch S. Haemagglutination, and haemagglutination - inhibition studies with a strain of Nebraska calf diarrhoea virus (bovine rotavirus). Intervirology. 1978; 9: 95-105. PubMed: https://pubmed.ncbi.nlm.nih.gov/201585/

41. Flewett TH, Bryden AS, Davies $H$. Virus particles in gastroenteritis. Lancet. 1973; 1497.

42. Fernel1us AL, Ritchie AE, Classick LG, Norman JO, Mebus CA. Cell culture adaptation and propagation of a reovirus-like agent of calf diarrhoea from a field outbreak in Nebraska. Archiv fiir die gesamte Virusforschung. 1972; 37: 114-130.

PubMed: https://pubmed.ncbi.nlm.nih.gov/4623479/ 